\title{
Left Vertebral Artery Arising Directly from the Aortic Arch
}

\author{
H. A. Amaratunga ${ }^{1}$, S. P. M. Peiris ${ }^{2}$, H. R. Gunasena ${ }^{1}$, J. K. Dissanayake ${ }^{1}$
}

\begin{abstract}
Objective of this article is to report a case of the vertebral artery arising as the $3^{\text {rd }}$ branch of the arch of the aorta and ascending up into the neck to enter the foramen transversarium of the $3^{\text {rd }}$ cervical vertebra. This knowledge regarding variations is beneficial for planning aortic arch surgeries or endovascular interventions.
\end{abstract}

Key words: vertebral artery, variation

\section{INTRODUCTION}

The vertebral artery arises as the first branch of the subclavian artery at the root of the neck. In $6 \%$ of individuals the left vertebral artery may arise from the arch of the aorta itself (1). Such variations warrant mention due to its importance in thoracic surgeries and vascular investigations. Here we report a case of the left vertebral artery arising from the aortic arch detected during cadaveric dissections.

\section{CASE REPORT}

During a routine dissection procedure on a cadaver of an 83 year old male conducted at the Department of Anatomy, 4 branches were detected arising from the aortic arch (Figure 1). Further dissections revealed the first branch to be the right bracheocephalic trunk, the second to be the left common carotid artery, the third to be the left vertebral artery and the fourth the left subclavian artery. The left vertebral artery was further dissected to expose its course up into the neck. When the vertebral artery arises from the subclavian artery it enters the foramen transversarium of the $6^{\text {th }}$ cervical vertebra (2). However in this case the vertebral artery travelled parallel to the left common carotid on its left and then turned posteriorly to enter the foramen of the $3^{\text {rd }}$ cervical vertebra. No other abnormality of the blood vessels or the heart was detected in the cadaver.

The arch of the aorta can have 4 branches arising from it and the left vertebral artery can arise from this site. This knowledge regarding variations is beneficial for planning aortic arch surgeries or endovascular interventions.

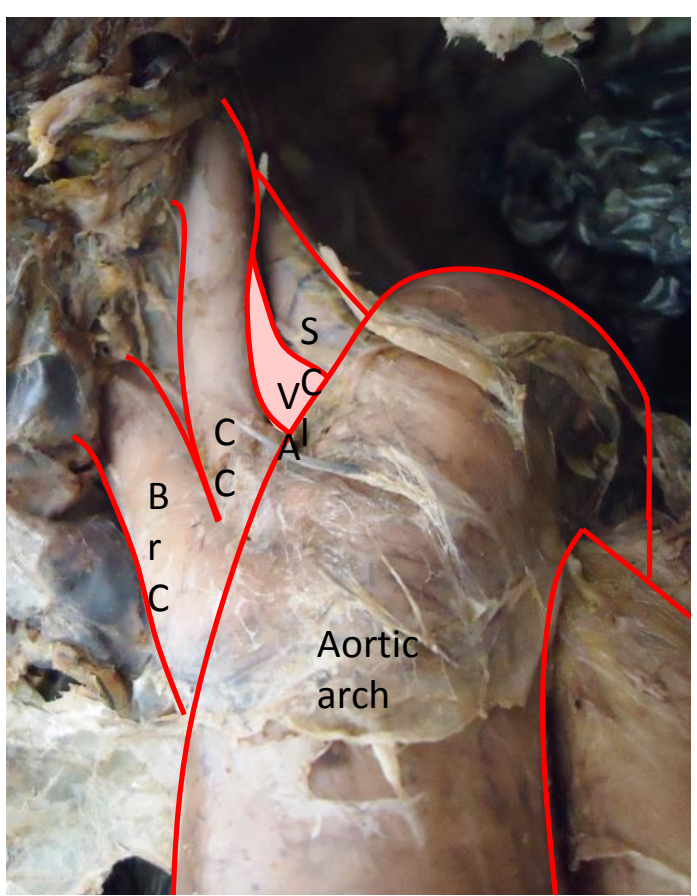

Figure 1: The four branches arising from the arch of the aorta. BrC-Brachiocephalic artery, $\mathbf{C C}$ - Common Carotid artery, VA Vertebral artery, SCl- Subclavian artery 
Amaratunga, H. A., PEIRIS, S. P. M., GUNASEnA, H. R., DiSSANAYAKE, J. K., Left vertebral artery arising directly from the aortic arch. Sri Lanka Anatomy Journal (SLAJ), 1(2): 52-53, 2017.

\section{REFERENCES}

1. Koenigsberg RA, Pereira L, Nair B. Unusual vertebral artery origins: examples and related pathology. Catheter Cardiovasc Interv 2003; 59:244-50.

2. McMinn RMH. Last's Anatomy Regional and Applied. $9^{\text {th }}$ ed. Churchill Livingstone. London. 2003. 444.

\section{CORRESPONDENCE}

Dr. H. A. Amaratunga

Department of Anatomy,

University of Peradeniya.

Email- himanipeiris@yahoo.com

Received: June 2017

Accepted: July 2017 